\title{
ausplotsR: An R package for rapid extraction and analysis of vegetation and soil data collected by Australia's Terrestrial Ecosystem Research Network
}

\section{Samantha Munroe ${ }^{1,2}$ (D) | Greg Guerin ${ }^{1,2}$ (D) \\ Bernardo Blanco-Martin $^{3}$ | Ben Sparrow ${ }^{1,2}$}

\author{
${ }^{1}$ School of Biological Sciences, The \\ University of Adelaide, Adelaide, South \\ Australia, Australia \\ ${ }^{2}$ Terrestrial Ecosystem Research Network \\ (TERN), University of Adelaide, Adelaide, \\ South Australia, Australia \\ ${ }^{3}$ Department of Agriculture and Fisheries, \\ Queensland Government, Garbutt, \\ Queensland, Australia

\section{Correspondence} \\ Samantha Munroe, Terrestrial Ecosystem \\ Research Network (TERN), University of \\ Adelaide, Adelaide, South Australia 5005, \\ Australia. \\ Email: samantha.munroe@adelaide.edu.au \\ Funding information \\ TERN is supported by the Australian \\ Government through the National \\ Collaborative Research Infrastructure \\ Strategy
}

Co-ordinating Editor: Duccio Rocchini

\begin{abstract}
The Terrestrial Ecosystem Research Network (TERN), Australia's national land ecosystem monitoring programme, measures critical environmental attributes from local to continental scale and generates quality data for research and land management. Since 2011, TERN has performed standardised field surveys and sampling across a national plot network. At each plot, TERN records vegetation structure, composition and diversity, soil characteristics, and collects plant and soil samples for analysis. At the time of submission, TERN has established over 750 plots and performed over 1,000 plot surveys across Australia. Here we present ausplotsR, an R package for the $R$ statistical computing environment that provides a user-friendly interface to rapidly import, visualise, and analyse TERN plot data. Easy-to-use functions extract the data and compile data tables that can be incorporated into a variety of statistical analysis, most notably multivariate applications requiring plant community data with standardised relative abundances. ausplots $R$ includes functions to calculate useful vegetation metrics, such as species presence/absence, cover, and basal area. The package also provides information on TERN's extensive soil and plant sample collection. We expect ausplotsR will help facilitate and advance ecological research and management throughout Australia and provide useful data for vegetation modellers globally.

\section{KEYWORDS}

Australia, big data, biodiversity, ecosystem monitoring, environmental modelling, plot survey, R statistical environment, Terrestrial Ecosystem Research Network (TERN)
\end{abstract}

\section{1 | INTRODUCTION}

Understanding the distribution and composition of terrestrial plant communities requires large amounts of reliable and diverse data. Examining important issues like the geography of plant functions
(Šímová et al. 2018), invasive species (Pyšek et al. 2020), or the maintenance of ecosystem services (Kubiszewski et al., 2020), requires wide-spread ecological community datasets (Kao et al. 2012; Kissling et al. 2018). The rapid increase of continental and global analyses in vegetation science (e.g. Velazco et al. 2017; Bruelheide et al. 2018; Jiménez-Alfaro et al. 2018) has also triggered the development of 
new tools and software that facilitate prompt data access and analysis (e.g. Maitner et al. 2018; Kattge et al. 2020). Thus, the challenge lies not only in constructing comprehensive datasets, but also in designing user-friendly data delivery systems that provide open access to standardised and complex databases (Chytrý et al. 2019).

The Terrestrial Ecosystem Research Network (TERN), Australia's ecosystem observatory, measures important terrestrial ecosystem attributes over time from local to continental scale at hundreds of sites across the country. TERN provides freely accessible data to empower scientists to detect and understand patterns and changes in terrestrial ecosystems. TERN is comprised of data collection platforms that gather complementary data at scales ranging from remote sensing to micro-meteorological observations (Sparrow et al. 2020a).

TERN's Ecosystem Surveillance platform performs standardised field surveys and sampling across a national plot network. This platform collects crucial data for effective monitoring of Australia's ecosystems, including vegetation structure and composition, soil characteristics, and soil and plant samples (Sparrow et al. 2020b). TERN has established over 750 plots across every major terrestrial environment in Australia (Figure 1), recoding $>5,000$ unique species and collecting $>65,000$ plant and soil samples for analysis (Table 1).

The ausplots $R$ package was designed for the R statistical computing environment (R Core Development Team, 2020) to provide free and simple access to the TERN Ecosystem Surveillance plot survey database (Guerin et al. 2020). The package has a straightforward workflow to enable a range of vegetation analyses. First, easy-tounderstand functions extract raw survey data for all plots within the network from a regularly updated database. Second, raw data can be incorporated into downstream functions that calculate a variety of metrics, such as species cover, fractional cover, and basal area. These functions distinguish ausplots $R$ from other vegetation databases because they provide a fast and reliable way to calculate some

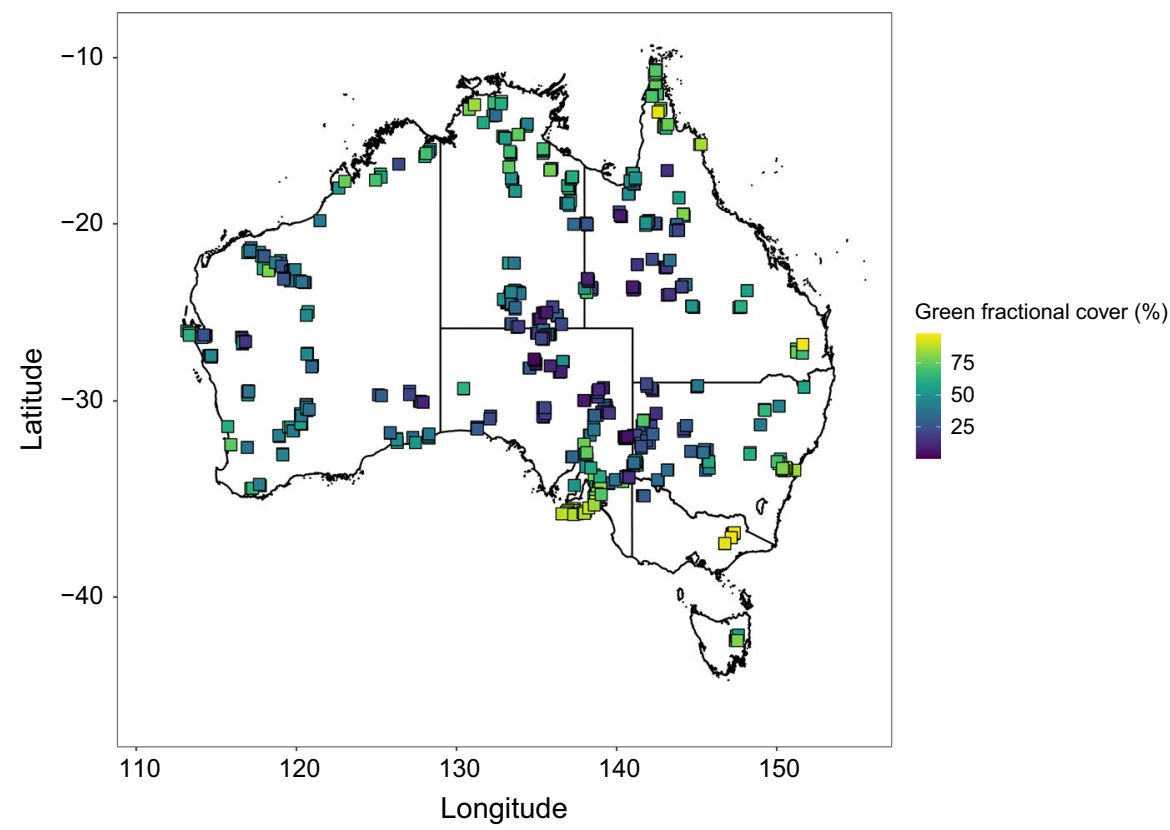

of the most common metrics in terrestrial research. ausplots $R$ also provides information on TERN's substantial soil and plant sample library, such as voucher numbers and the date and location samples were collected. Data are formatted to support compatibility with global (e.g. Kattge et al. 2020) and Australian plant trait data sets (e.g. Falster et al., in review) and can be integrated with additional TERN data products. The goal of ausplotsR is to facilitate quality ecosystem research and effective land management across Australia through delivery and pre-processing of field data. Instant access to continental-scale plant community data in the $\mathrm{R}$ environment provides a valuable resource to vegetation scientists and modellers for testing ecological ideas, tools, and methods.

\section{1 | TERN plot survey methods}

TERN plots are surveyed using the "AusPlots Rangelands" method, composed of modules to collect vegetation and soil data (Table 2; also see Sparrow et al. 2020b). Here we provide a short overview of the modules used to collect data available through ausplotsR. Onehectare plots are established in a homogenous area of terrestrial vegetation. Vegetation structure and composition are measured using the point-intercept module. Ten transects $100 \mathrm{~m}$ long are laid out in a grid pattern spaced $20 \mathrm{~m}$ apart. Species identity, growth form, height, and systematic absences (e.g. bare ground) are recorded at 1-m points along transects, resulting in 1,010 survey points. Vouchers of each species are collected and sent to herbaria for identification.

Soil modules collect information on a range of physical and chemical soil characteristics. A $1 \mathrm{~m}$ deep pit is dug in the southwest corner of the plot, which enables the description of the upper soil profile. TERN measures soil pH, bulk density, electrical conductivity, texture, colour, and structure. Soil samples are also collected at nine sub-sites across the plot to assess microhabitat variability and enable metagenomic
FIGURE 1 TERN AusPlots monitoring plot locations as generated within the package coded by percent fractional green cover 
analysis of environmental DNA. Plant and soil samples are tracked using alphanumeric barcode labels and stored for later analysis.

AusPlots data are collected via the AusScribe app, a custom Android/iOS app that is designed for operation on tablets (Tokmakoff et al. 2016). As observers complete data entry for a plot, they upload collected data from the AusScribe app to a backend system which

TAB LE 1 TERN survey and sample records available through ausplotsR

\begin{tabular}{ll} 
Data type & Count \\
\hline Number of plots surveyed & 667 \\
Number of plots revisited & 106 \\
Number of plant voucher specimens collected & 41,141 \\
Number of leaf tissue samples available & 52,065 \\
Number of plant species collected & 5,245 \\
Number of point intercepts & 872,761 \\
Number of soil bulk density samples & 1,675 \\
Number of soil metabarcoding samples available & 8,091 \\
Total number of soil samples available & 17,082 \\
\hline
\end{tabular}

makes the data available for curation by TERN staff. Once curated, visits are marked as published and automatically made available via ausplotsR. This data pipeline ensures new data is made rapidly available.

\section{2 | The ausplotsR package}

The ausplotsR package (CRAN: https://CRAN.R-project.org/packa ge=ausplotsR; latest development version and patches: https:// github.com/ternaustralia/ausplotsR) provides access to most data modules. ausplots $R$ sources its data via a dedicated server stack running inside a Virtual Machine in the Australian Research Data Common's (ARDC's) NECTAR research cloud. The stack contains a number of services which: (a) expose the published AusPlots data for external use, (b) collect usage statistics; (c) reverse-proxy the application programming interface (API) for scalability and provide threat protection; and (d) authenticate/authorise users for fine-grained data access control. This open-source stack is available at: https:// github.com/ternandsparrow/swarm-rest. ausplotsR functions enable users to quickly read and prepare plot data for ecological analysis.

TAB LE 2 Modules in the AusPlots Rangelands monitoring method and the data types available from the package ausplotsR (Sparrow et al. 2020b)

\begin{tabular}{|c|c|c|c|}
\hline Module & Protocol & Application & $\begin{array}{l}\text { Data available in } \\
\text { ausplotsR? }\end{array}$ \\
\hline Plot layout & $\begin{array}{l}\text { Accurate layout using DGPS; installation of } \\
\text { permanent markers. }\end{array}$ & $\begin{array}{l}\text { Accurate relocation; remote sensing } \\
\text { validation }\end{array}$ & Yes \\
\hline \multicolumn{4}{|l|}{ Vegetation } \\
\hline Photo-panoramas & $\begin{array}{l}\text { Collection of } 360^{\circ} \text { photographs from three } \\
\text { points }\end{array}$ & $\begin{array}{l}\text { Computer vision analysis, point clouds and } \\
\text { measures of basal area }\end{array}$ & No \\
\hline Vouchering & Collection of vascular plant species & $\begin{array}{l}\text { Taxonomy; spatial/temporal analysis of } \\
\text { presence-absence }\end{array}$ & Yes \\
\hline Tissue samples & $\begin{array}{l}\text { Collection of single tissue samples from vascular } \\
\text { plants }\end{array}$ & Genetic/isotopic analysis & Yes \\
\hline Point-intercept & $\begin{array}{l}\text { Collection of species, height, phenology, } \\
\text { growth-form, senescence at } 1,010 \text { points }\end{array}$ & $\begin{array}{l}\text { Change in relative abundance, cover and } \\
\text { structure; remote sensing validation }\end{array}$ & Yes \\
\hline Basal area & $\begin{array}{l}\text { Collection by species using basal wedge at nine } \\
\text { points }\end{array}$ & Convertible to biomass & Yes \\
\hline Structural summary & $\begin{array}{l}\text { Recording of three dominant species in each of } \\
\text { three strata (upper, mid, ground) }\end{array}$ & Community descriptions & Yes \\
\hline Leaf area Index & $\begin{array}{l}\text { Collection of at least } 50 \text { evenly spaced readings } \\
\text { with the LiCor LAI 2,200 LAI meter }\end{array}$ & $\begin{array}{l}\text { Ecophysiological modelling; remote sensing } \\
\text { validation }\end{array}$ & No \\
\hline \multicolumn{4}{|l|}{ Soils and landscapes } \\
\hline Plot description & $\begin{array}{l}\text { Record location, substrate, microtopography, } \\
\text { erosion/disturbance }\end{array}$ & $\begin{array}{l}\text { Assessment of characteristics/impact of } \\
\text { disturbance }\end{array}$ & Yes \\
\hline $\begin{array}{l}\text { Soil pit } \\
\text { characterisation }\end{array}$ & $\begin{array}{l}\text { Collection of soil samples/data at } 10 \mathrm{~cm} \\
\text { increments or identifiable horizons to } 1 \mathrm{~m}\end{array}$ & $\begin{array}{l}\text { Characterisation and classification. Correlate } \\
\text { with vegetation }\end{array}$ & Yes \\
\hline $\begin{array}{l}\text { Sub-site } \\
\text { characterisation }\end{array}$ & $\begin{array}{l}\text { Collection of nine samples in differing } \\
\text { microhabitats at } 0-10,10-20 \text { and } 20-30 \mathrm{~cm}\end{array}$ & Soil variability across plot & Yes \\
\hline Bulk density & $\begin{array}{l}\text { Collection of three measures at the soil pit at } \\
0-10,10-20 \text { and } 20-30 \mathrm{~cm}\end{array}$ & Conversion to volumetric measures & Yes \\
\hline Soil metagenomics & Collection of nine samples & Identify biota & Yes \\
\hline
\end{tabular}


Next, we review key ausplotsR functions to extract, visualise, and analyse plot data (Table 3).

\subsection{1 | Data extraction}

Data are extracted using the function 'get_ausplots' (Table 4). By default, the 'get_ausplots' function extracts a list of data tables for the point-intercept ('\$veg.PI') and vegetation voucher ('\$veg.vouchers') modules for all plots and visits. It also provides a site information table ('\$site.info') which describes plot details and environmental features. Using these data tables, TERN's specimen collection can be cross-referenced against site information and vegetation metrics.

Arguments of 'get_ausplots' allow users to select data for individual plots ('my.Plot_IDs'), rectangular spatial coordinates ('bounding box'), plant families ('family_search'), or species (see Data Format).

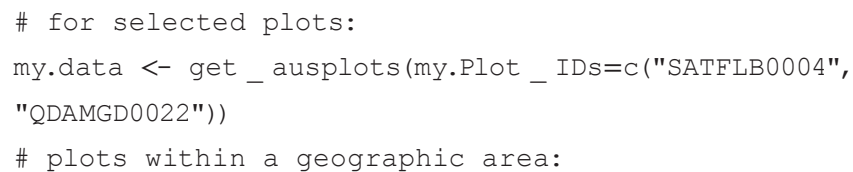

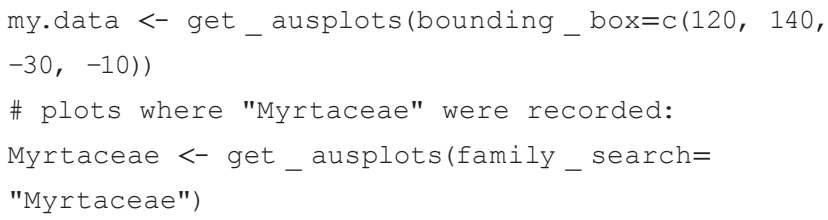

Users can request data not extracted by default, like basal wedge data ('basal.wedge=TRUE') or soil characteristics ('soil_character=TRUE'). Once extracted, data tables can be incorporated into various downstream processing functions that calculate vegetation indices (Figure 2).

\subsection{2 | Data format}

All ausplotsR data tables list data by plot and visit. Unique plots are identified by their 'site_location_name' (plot ID used to distinguish each unique plot) and 'site_location_visit_id' (numeric value that delineates each visit). 'Site_location_name' is an alphanumeric value that indicates State/Territory (e.g. Western Australia, W.A.; South Australia, S.A., etc.) and bioregion (Thackway \& Cresswell, 1995),

\begin{tabular}{|c|c|}
\hline Function & Description \\
\hline ausplots_visual & $\begin{array}{l}\text { Generates a set of graphical displays representing TERN AusPlots data } \\
\text { based on geographic locations and vegetation attributes from the } \\
\text { plot-based point intercepts (as generated by 'get_ausplots' and other } \\
\text { pre-processing functions) }\end{array}$ \\
\hline basal_area & $\begin{array}{l}\text { Calculates basal area (or number of basal wedge hits) for each plot, } \\
\text { using the raw basal wedge data returned from 'get_ausplots' }\end{array}$ \\
\hline fractional_cover & $\begin{array}{l}\text { Calculates fractional cover (i.e., the proportional cover of green } \\
\text { vegetation, dead vegetation and bare substrate) based on plot-based } \\
\text { point-intercept data (as generated by 'get_ausplots') }\end{array}$ \\
\hline get_ausplots & $\begin{array}{l}\text { This function is the starting point for accessing data through the } \\
\text { ausplotsR package. It extracts the data }\end{array}$ \\
\hline growth_form_table & $\begin{array}{l}\text { Generates occurrence matrices for plant growth forms in plots as } \\
\text { desired based on presence/absence, percent cover or species richness } \\
\text { (i.e., the number of species assigned to a growth form). The input is } \\
\text { a data frame of raw point intercept data generated using the 'get_ } \\
\text { ausplots' function }\end{array}$ \\
\hline optim_species & $\begin{array}{l}\text { This function applies different optimisation methods to select a subset } \\
\text { of plots that maximise species accumulation. The function operates } \\
\text { under the Maximum Covering Problem framework }\end{array}$ \\
\hline plot_opt & $\begin{array}{l}\text { This function plots different species accumulation curves obtained } \\
\text { through different optimisers in the 'optim_species' function }\end{array}$ \\
\hline single_cover_value & $\begin{array}{l}\text { Calculates a single vegetation cover value per site based on the plot- } \\
\text { based point intercept data generated by 'get_ausplots'. Cover can be } \\
\text { subsetted to vegetation that has a specified minimum or maximum } \\
\text { height and/or by plant growth forms }\end{array}$ \\
\hline species_list & $\begin{array}{l}\text { Nice species lists based on the vegetation voucher module of Ausplots } \\
\text { generated using the 'get_ausplots' function }\end{array}$ \\
\hline species_table & $\begin{array}{l}\text { This function takes a data frame of individual raw point intercept hits } \\
\text { generated using the 'get_ausplots' function, and generates species } \\
\text { occurrence matrices as desired based on presence/absence, cover, } \\
\text { frequency or Importance Value Index (IVI) }\end{array}$ \\
\hline
\end{tabular}

TABLE 3 Descriptions of ausplotsR functions 
TAB LE 4 Data tables generated by 'get_ausplots()'

\begin{tabular}{|c|c|c|}
\hline Module & $\begin{array}{l}\text { 'get_ausplots()' data } \\
\text { table }\end{array}$ & Description \\
\hline${ }^{a}$ Plot layout & \$site.info & Data frame with basic site information including location \\
\hline${ }^{\text {a Point-intercept }}$ & \$veg.PI & Data frame with individual point intercept data \\
\hline${ }^{a}$ Vascular plant vouchering and tissue samples & \$veg.vouch & $\begin{array}{l}\text { Data frame with rows for each voucher and information on } \\
\text { species determinations and silica-dried tissue samples }\end{array}$ \\
\hline \multicolumn{3}{|l|}{ Soil and Landscapes } \\
\hline Structural summary & \$struct.summ & Data frame with vegetation structural summaries for each plot \\
\hline Sub-site characterisation and soil metagenomics & \$soil.sub & $\begin{array}{l}\text { Data frame with details of soil subsites within each plot } \\
\text { including sample barcode identification }\end{array}$ \\
\hline \multicolumn{3}{|l|}{ Metadata } \\
\hline Variable dictionary & \$metadata.dictionary & $\begin{array}{l}\text { Lists and describes each variable and corresponding values in } \\
\text { each data frame }\end{array}$ \\
\hline${ }^{\mathrm{a}}$ Data citation & \$citation & Auto-generated citation for the data extracted \\
\hline
\end{tabular}

${ }^{\text {a}}$ Extracted by default.

FIGURE 2 Workflow of the ausplotsR package, demonstrating how raw data tables generated from 'get_ausplots()' can be incorporated in processing and downstream functions

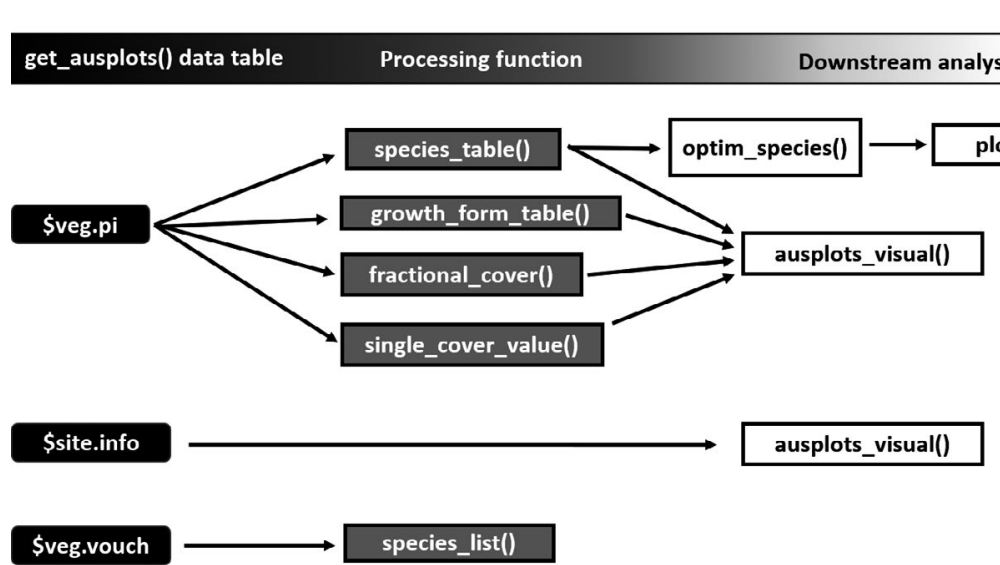

\$veg.basal $\longrightarrow$ basal_area() as well as a sequential number based on the number of plots in that bioregion. For example, the 'site_location_name' SAAFLB0008 indicates the plot is in South Australia (SAA), in the Flinders Lofty Block (FLB) bioregion, and was the eighth plot in that bioregion. 'Site_location_name' and 'site_location_visit_id' are concatenated into the 'site_unique' field that identifies both unique plots and visits.

The point-intercept ('\$veg.PI') and vegetation voucher ('\$veg. vouchers') data tables include columns with taxonomic information: 'family', 'genus', 'specific_epithet', 'genus_species' (genus and specific_epithet combined), 'infraspecific_epithet' (e.g. subspecies, variety), and 'authorship'. ausplots $R$ provides two species name options: 'herbarium_determination' and 'standardised_name'. The 'herbarium_determination' column contains species identifications to the lowest possible taxonomic rank provided by herbaria. However, nomenclature sometimes differs between States (this is rare). The 'herbarium_determination' values also include vegetation identifications for incomplete, dead, or generic specimens (e.g. Dead Tree/Shrub, Annual Grass).

Alternatively, species identifications can be taken from the 'standardised_name' field. The 'standardised_name' values are based on 'herbarium_determination' values standardised to match the most widely accepted synonym according to "World Flora Online" (www.world floraonline.org). This ensures scientific names will not differ between States/Territories and increases consistency with global databases. It 


\section{SATFLB0007-53709}

- Bare ground

- Non-photosynthetic vegetation

- Photosynthetic vegetation

- NA

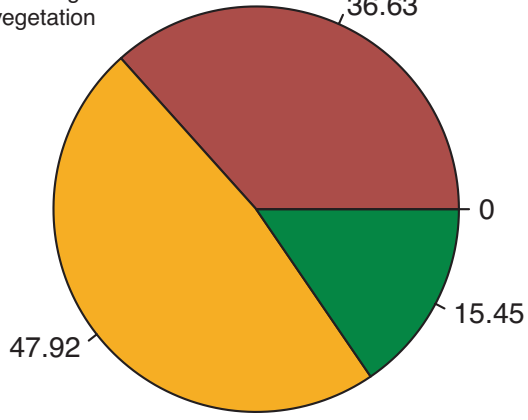

SATFLB0007-53709

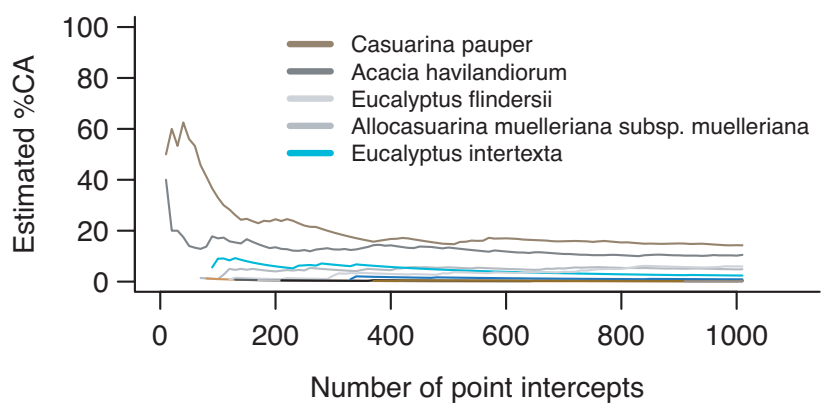

SATFLB0007-53709

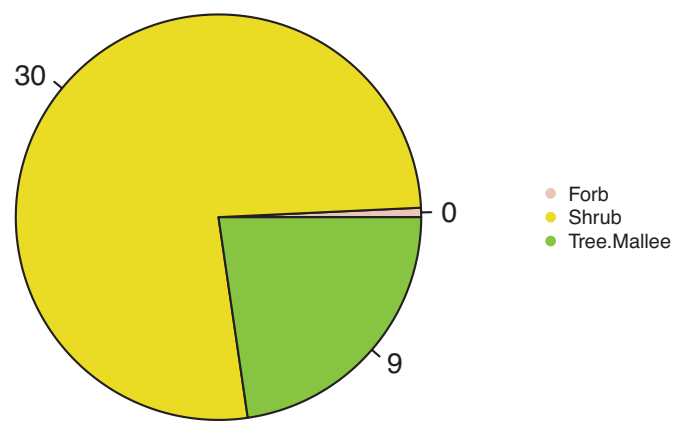

SATFLB0007-53709

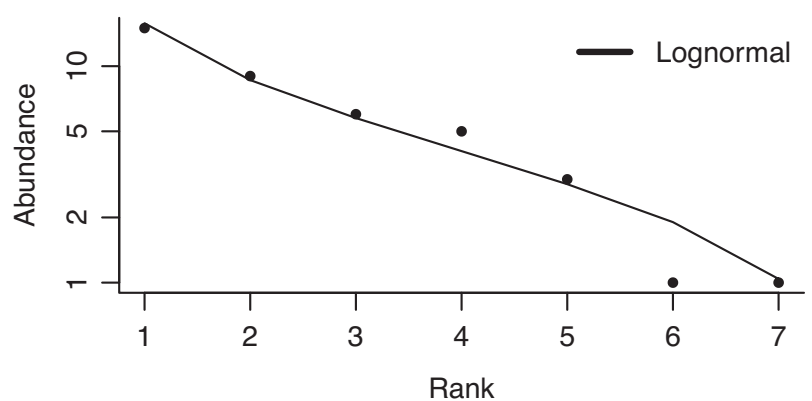

FIGURE 3 Example of data presentation panels for a single plot visit using 'ausplots_visual()': (a) fractional vegetation cover; (b) the relative abundance of plant growth forms; (c) cumulative estimates of percent cover by species as point intercept hits are taken across the plot (Guerin et al. 2017); (d) Whittaker plot (Whittaker 1965) of species' relative abundance fitted with a lognormal SAD curve

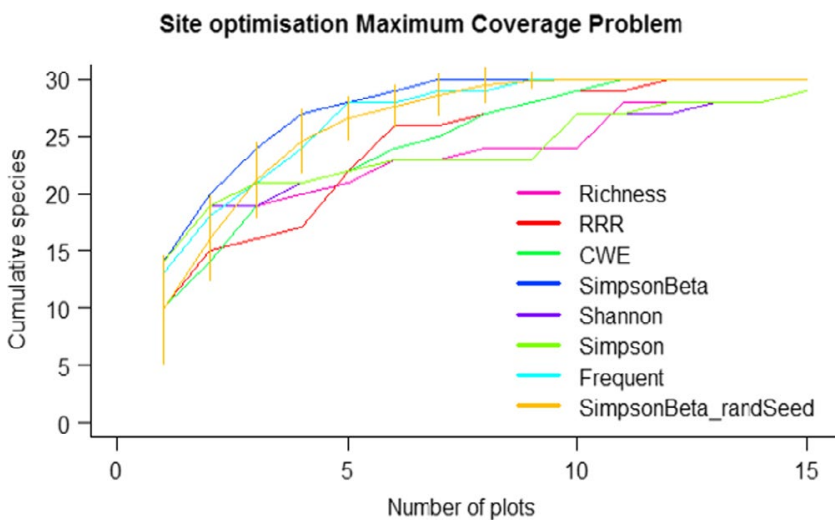

FIGURE 4 Species accumulation plot comparing different biodiversity metrics included in 'optim_species'. The image has been created using the 'dune' data set from the vegan package as an input, selecting 15 plots, and 60 iterations to calculate the most frequently selected plots based on random starts

also excludes non-standard entries like "dead" identifications. The remaining taxonomic fields are derived from the 'standardised_name'.

Plot data extractions can be filtered by 'herbarium_detemination' or 'standardised_name':

\#plot and voucher records where "Eucalyptus

moderata" was identified:

Eucalyptus _ moderata <- get _ausplots(herbarium _ determination _ search="Eucalyptus moderata")

\subsection{3 | Data processing and calculation of vegetation indices}

\section{Community composition matrices}

The 'species_table' function takes the data table of individual pointintercept hits ('\$veg.PI') and returns species occurrence matrices. The 'species_table' function can calculate species presence/absence, percent cover, frequency (based on occurrences on different transects), or Importance Value Index. Users can select the preferred species name option from 'standardised_name', 'herbarium determination', or 'genus_species'. For example, to compare species level cover:

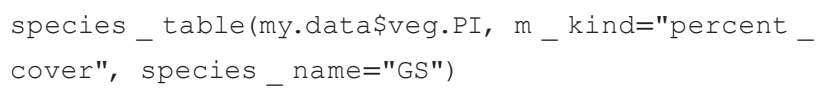

Details on how vegetation indices are calculated are in the help manual.

\section{Vegetation cover}

Several functions in ausplotsR calculate different aspects of vegetation (and ground) cover based on raw point-intercept input data 


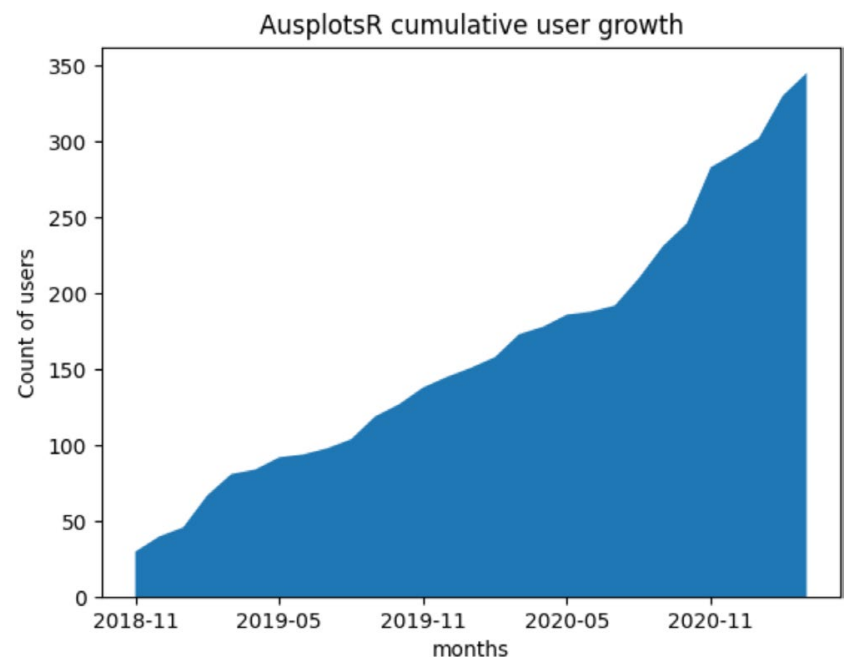

FIGURE 5 Cumulative number of unique users who extracted TERN Ecosystem Surveillance data via ausplotsR over two years

('\$veg.PI'). The 'growth_form_table' function generates occurrence matrices for plant growth forms based on presence/absence, cover, or species richness:

growth_form _table(my.data\$veg.PI,

m_kind="percent_ cover")

Other functions calculate fractional cover (i.e. proportional cover of living vegetation, dead litter and bare ground; 'fractional_cover'; Figure 1), cover of individual growth forms subset by height ('single cover_value'), and the cross-sectional area of tree trunks measured through the basal wedge module ('basal_area'). The relative cover of species, plant growth forms, and fractional cover can be illustrated per plot using the function 'ausplots_visual' (Figure 3).

\section{Optimising species accumulation}

The 'optim_species' function applies different biodiversity metrics as optimisers to select a subset of plots that maximise species accumulation. The framework underlying this function is the Maximal Coverage Problem, applied in conservation biology to design reserves (Church et al. 1996). The function identifies plots that will "protect" the maximum number of species in a limited number of sites. The biodiversity metrics included are species richness (biodiversity hotspots), range rarity richness (high biodiversity and uniqueness; Guerin \& Lowe, 2015), corrected weighted endemism (areas with range-restricted endemic species; Crisp et al. 2001), Shannon-Wiener diversity index and the Simpson diversity index (which include species relative abundances), and the Simpson dissimilarity (maximises species turnover; Baselga \& Leprieur, 2015). Users specify the number of plots to select, and each optimiser selects the subset of plots that accumulates the largest number of species. To do this, biodiversity metrics are applied only to species occurrences within the data set. The 'optim_species' function can also visualise the optimisations (Figure 4). The input data are a species versus sites matrix; thus, it can be used with the data generated with 'species_table' or with any other vegetation data set.

\section{3 | Data licence and authorship guidelines}

Data provided by TERN through ausplotsR are distributed by a CCBY Creative Commons licence (https://creativecommons.org/licen ses/by/4.0/). Publications using data provided by TERN retrieved using ausplotsR should cite both the data and the package. The suggested citation for the plot data is automatically generated by ausplots $R$ when you extract data.

\section{4 | Applications and uptake}

ausplotsR makes it easy for scientists to quickly access and integrate plot data into their analyses. Data are imported directly into $\mathrm{R}$, avoiding the need to gain permission to access data or store data in numerous csv files. Convenient data formatting supports seamless integration with a range of ecological, statistical, and graphical R packages with repeatable, self-contained script workflow (e.g. Manion et al. 2017; Oksanen et al. 2017), making it a useful exploratory data set for vegetation scientists. For example, ausplotsR and TERN plot data have been used to determine what factors affect the biosynthetic domain composition of secondary metabolites encoded by soil bacteria (Lemetre et al. 2017), and to validate remotely sensed estimates of forest cover in dryland biomes (Bastin et al. 2017). Other examples of data applications are described in Sparrow et al. (2020b). Because ausplotsR is embedded in R's software environment, TERN plot data can easily be enriched with additional data (e.g. climatic or altitude).

In recent years, the package has seen significant uptake from users. At the time of writing, we have served over ten thousand requests for data to over 350 users since early formats of the package were released in 2018 (Figure 5). These users have downloaded 5,000,000 sites of data and 1.2 billion total records. We expect ausplotsR will continue to enable ecological research on Australian ecosystems and enhance opportunities for vegetation modelling internationally.

Importantly, the "AusPlots Rangelands" method and TERN data model (i.e. the way data items are connected and modelled, https:// linkeddata.tern.org.au) could be adapted by users to create their own data management system. Similarly, ausplotsR code can be extracted to calculate vegetation indices for unaffiliated data sets. The function 'optim_species' can already incorporate non-TERN data.

\section{5 | Concluding remarks}

For over a decade, TERN has provided comprehensive and researchready data on Australia's ecosystems. With ausplotsR, it is easier than ever for scientists to access Australia's only database of standardised terrestrial ecosystem measurements. ausplots $R$ provides unfettered access to a broad and high-quality data set combining information on different data streams and metrics in a user-friendly format. Data not provided through ausplots $R$, such as photo-panoramas and physical samples, can be requested from TERN (www.tern.org.au). TERN 
continues to expand its plot network across Australia and enhance the database with new information and resources. ausplots $R$ will be updated as data becomes available. New and improved tools will also be added to the package in subsequent versions.

\section{ACKNOWLEDGEMENTS}

We acknowledge the TERN Ecosystem Surveillance field team and volunteers who work tirelessly to collect TERN plot data. We also acknowledge the support of TERN by the National Collaborative Research Infrastructure Strategy.

\section{AUTHOR CONTRIBUTIONS}

AT and GG conceived the package; AT, GG, TS, SM, IMF and BBM wrote R functions and documentation; BS collected data; SM drafted the paper. All authors contributed to the paper and developed the package and data set.

\section{DATA AVAILABILITY STATEMENT}

Data sharing not applicable to this article as no data sets were generated or analysed during the current study.

\section{ORCID}

Samantha Munroe iD https://orcid.org/0000-0001-7827-1028

Greg Guerin iD https://orcid.org/0000-0002-2104-6695

Irene Martín-Forés (iD https://orcid.org/0000-0003-3627-0347

Ben Sparrow iD https://orcid.org/0000-0003-2566-1895

\section{REFERENCES}

Baselga, A. \& Leprieur, F. (2015) Comparing methods to separate components of beta diversity. Methods in Ecology and Evolution, 6, 10691079. https://doi.org/10.1111/2041-210X.12388

Bastin, J.-F., Berrahmouni, N., Grainger, A., Maniatis, D., Mollicone, D., Moore, R. et al (2017) The extent of forest in dryland biomes. Science, 356, 635-638. https://doi.org/10.1126/science.aam6527

Bruelheide, H., Dengler, J., Purschke, O., Lenoir, J., Jiménez-Alfaro, B., Hennekens, S.M. et al (2018) Global trait-environment relationships of plant communities. Nature Ecology \& Evolution, 2, 1906-1917. https://doi.org/10.1038/s41559-018-0699-8

Church, R.L., Stoms, D.M. \& Davis, F.W. (1996) Reserve selection as a maximal covering location problem. Biological Conservation, 76, 105112. https://doi.org/10.1016/0006-3207(95)00102-6

Chytrý, M., Chiarucci, A., Pärtel, M., Pillar, V.D., Bakker, J.P., Mucina, L. et al (2019) Progress in vegetation science: Trends over the past three decades and new horizons. Journal of Vegetation Science, 30, 1-4. https://doi.org/10.1111/jvs.12697

Crisp, M.D., Laffan, S., Linder, H.P. \& Monro, A. (2001) Endemism in the Australian flora. Journal of Biogeography, 28, 183-198. https://doi. org/10.1046/j.1365-2699.2001.00524.x

Falster, D., Gallagher, R., Wenk, E., Wright, I., Indiarto, D. \& Baxter, C. et al (in review) Austraits - a curated plant trait database for the Australian flora.

Guerin, G.R. \& Lowe, A.J. (2015) 'Sum of inverse range-sizes'(SIR), a biodiversity metric with many names and interpretations. Biodiversity and Conservation, 24, 2877-2882. https://doi.org/10.1007/s1053 1-015-0977-6

Guerin, G.R., Saleeba, T., Munroe, S., Blanco-Martin, B., Martín-Forés, I. \& Tokmakoff, A. (2020) ausplotsR: TERN AusPlots analysis package. $\mathrm{R}$ package version 1.2 .
Guerin, G.R., Sparrow, B., Tokmakoff, A., Smyth, A., Leitch, E., Baruch, Z. \& Lowe, A.J. (2017) Opportunities for integrated ecological analysis across inland Australia with standardised data from Ausplots Rangelands. PloS one, 12(1), e0170137.

Jiménez-Alfaro, B., Suárez-Seoane, S., Chytrý, M., Hennekens, S.M., Willner, W., Hájek, M. et al (2018) Modelling the distribution and compositional variation of plant communities at the continental scale. Diversity and Distributions, 24, 978-990. https://doi.org/10.1111/ ddi.12736

Kao, R.H., Gibson, C.M., Gallery, R.E., Meier, C.L., Barnett, D.T., Docherty, K.M. et al (2012) NEON terrestrial field observations: designing continental-scale, standardized sampling. Ecosphere, 3, art115. https://doi.org/10.1890/ES12-00196.1

Kattge, J., Bönisch, G., Díaz, S., Lavorel, S., Prentice, I.C., Leadley, P. et al (2020) TRY plant trait database - enhanced coverage and open access. Global Change Biology, 26, 119-188. https://doi.org/10.1111/ gcb.14904

Kissling, W.D., Ahumada, J.A., Bowser, A., Fernandez, M., Fernández, N., García, E.A. et al (2018) Building essential biodiversity variables (EBVs) of species distribution and abundance at a global scale. Biological Reviews, 93, 600-625. https://doi.org/10.1111/brv.12359

Kubiszewski, I., Costanza, R., Anderson, S. \& Sutton, P. (2020) The future value of ecosystem services: Global scenarios and national implications. In: Environmental Assessments. Edward Elgar Publishing.

Lemetre, C., Maniko, J., Charlop-Powers, Z., Sparrow, B., Lowe, A.J. \& Brady, S.F. (2017) Bacterial natural product biosynthetic domain composition in soil correlates with changes in latitude on a continentwide scale. Proceedings of the National Academy of Sciences, 114, 11615-11620. https://doi.org/10.1073/pnas.1710262114

Maitner, B.S., Boyle, B., Casler, N., Condit, R., Donoghue, J. II, Durán, S.M. et al (2018) The bien $r$ package: A tool to access the Botanical Information and Ecology Network (BIEN) database. Methods in Ecology and Evolution, 9, 373-379. https://doi.org/10.1111/2041-210X.12861

Manion, G., Lisk, M., Ferrier, S., Nieto-Lugilde, D., Mokany, K. \& Fitzpatrick, M.C. (2017) gdm: Generalized Dissimilarity Modeling. R package version 1.3.

Oksanen, J., Blanchet, F.G., Friendly, M., Kindt, R., Legendre, P., McGlinn, D. et al (2017) vegan: Community Ecology Package. R package version 2.6.

Pyšek, P., Hulme, P.E., Simberloff, D., Bacher, S., Blackburn, T.M., Carlton, J.T. et al (2020) Scientists' warning on invasive alien species. Biological Reviews, 95, 1511-1534. https://doi.org/10.1111/brv.12627

R Core Development Team (2020) R: A language and environment for statistical computing. In. R Foundation for Statistical Computing, Vienna, Austria.

Šímová, I., Violle, C., Svenning, J.-C., Kattge, J., Engemann, K., Sandel, B. et al (2018) Spatial patterns and climate relationships of major plant traits in the New World differ between woody and herbaceous species. Journal of Biogeography, 45, 895-916. https://doi.org/10.1111/ jbi.13171

Sparrow, B.D., Edwards, W., Munroe, S.E.M., Wardle, G.M., Guerin, G.R., Bastin, J.-F. et al (2020a) Effective ecosystem monitoring requires a multi-scaled approach. Biological Reviews, 95, 1706-1719. https://doi. org/10.1111/brv.12636

Sparrow, B.D., Foulkes, J.N., Wardle, G.M., Leitch, E.J., Caddy-Retalic, S., van Leeuwen, S.J. et al (2020b) A vegetation and soil survey method for surveillance monitoring of rangeland environments. Frontiers in Ecology and Evolution, 8, 157. https://doi.org/10.3389/ fevo.2020.00157

Thackway, R. \& Cresswell, I., Eds (1995) An Interim Biogeographic Regionalisation for Australia: a framework for establishing the national system of reserves, Version 4.0. Australian Nature Conservation Agency, Canberra.

Tokmakoff, A., Sparrow, B., Turner, D. \& Lowe, A. (2016) AusPlots Rangelands field data collection and publication: Infrastructure for 
ecological monitoring. Future Generation Computer Systems, 56, 537549. https://doi.org/10.1016/j.future.2015.08.016

Velazco, S.J.E., Galvão, F., Villalobos, F. \& De Marco Júnior, P. (2017) Using worldwide edaphic data to model plant species niches: an assessment at a continental extent. PLoS One, 12, e0186025. https:// doi.org/10.1371/journal.pone.0186025

Whittaker, R.H. (1965) Dominance and diversity in land plant communities: numerical relations of species express the importance of competition in community function and evolution. Science, 147, 250-260.
How to cite this article: Munroe S, Guerin G, Saleeba T, et al. ausplotsR: An R package for rapid extraction and analysis of vegetation and soil data collected by Australia's Terrestrial Ecosystem Research Network. J Veg Sci. 2021;32:e13046. https://doi.org/10.1111/jvs.13046 